\title{
Analysis of Influence on the Grid of Input Part of Special Power Source 113 kW / 1 kA DC
}

\author{
Jiř́ Fořr ${ }^{1)}$ and Martin Pittermann ${ }^{2)}$ \\ 1) 2) Department of Electromechanics and Power Electronics, University of West Bohemia, Pilsen, Czech Republic \\ e-mail: ${ }^{1)}$ fort@kev.zcu.cz, ${ }^{2)}$ pitterma@kev.zcu.cz
}

\begin{abstract}
This paper compares some variants of power circuit configurations for a special power DC source $110 \mathrm{~V} / 1 \mathrm{kA}$. The requirement for the source was to ensure minimum ripple of the output current and reduced EMCdisturbance generated from this DC-source to the supply network and to other surrounding equipments.
\end{abstract}

Keywords - power quality, static power converter, 12-pulse rectifier, higher order harmonics.

\section{INTRODUCTION}

The article describes a study, which compares the possibilities of designing a special controlled semiconductor converter with the output DC current $1 \mathrm{kA}$, $110 \mathrm{~V}$ (nominal power $113 \mathrm{~kW}$ ) for experimental thermal equipment. This source was designed for supply of an experimental device modelling the heat transfer to the liquid (heat is generated by ohmic losses in a massive conductor). Therefore the output can realize a relatively high power $(113 \mathrm{~kW})$, relatively high current (approx. $1 \mathrm{kA}$ ) and above all low noise emission for the realized experiment (temperature sensing with thermocouples) and a low interference emission to the surrounding devices (additional installation in "non-industrial area" and minimization of interventions in the existing power supply network).

Originally (in older similar laboratory objects), a rotary set consisting of an induction motor driven dynamo was used for these purposes. It is also intended to be used in the non-commercial sphere (i.e. research + teaching), which led to low cost requirements (and the unique construction of just one "prototype").

The initial phase of "theoretical considerations" was "interrupted so far" by the comparison of the different simulation result variants and estimated approximate price estimates of these variants.

\section{SPECIFIC REQUIREMENTS}

The described power source for this experimental thermal device needs to realize these requirements:

- maximum output current $1 \mathrm{kA}$ and voltage $110 \mathrm{~V}$,

- possibility of fast response (in full range from $0 \%$ to $100 \%$ during some milliseconds),

- minimum ripple of the output DC-current,

- low EMC-disturbance (low interference) from source to the supply network (and to other devices),

- long service life and maintenance-free,

- small weight, small dimensions, low cost, etc.

\section{CONSIDERED VARIANTS}

Described study compared these variants:

a) Non-controlled rectifier with special controlled transformer (so called "booster") - disadvantages of this variant are expensive solution (in comparing with the other more modern variants described in other paragraphs), maintenance of the transformer, relatively slow response.

b) Non-controlled rectifier with AC converter with thyristors (possibility of using relatively cheap additional AC voltage converter, see chapter $\mathrm{V}$ ).

c) Full controlled rectifier or half-controlled rectifier (disadvantages of this variant: high ripple of the output DC current, high lagging reactive power).

d) Non-controlled rectifier with the DC-converter (stepdown buck converter with IGBT, see chapter VI and VII).

e) Modern types of controlled rectifiers (i.e. voltage source active rectifier VSAR, current source active rectifier CSAR or Wienna rectifier etc.)

f) Combination of these variants - for example combination of some number of "independent" non-controlled units with switching on/off and one full controlled unit (described in previous paragraphs).

Described study prefers configurations with 12-pulse rectifiers with a special transformer (for example Yy0d11transformer etc.). These 12-pulse configurations bring the low EMC-disturbance (in comparing with standard 6-pulse rectifier).

\section{USED METHOD FOR COMPARING}

These variants were compared by simulation in software "Matlab/Simulink" and "Plecs". These obtained simulation results are shown during full-power regime (nominal output voltage and nominal output DC-current) and during reduced-power regime (approximately half nominal voltage, half nominal current and quarter nominal output power).

\section{AC-CONVERTER AND NON-CONTROLLED RECTIFIER}

Figure 1 shows the power circuit (i.e. 3-phase AC voltage-controller with $3 \times 2=6$ thyristors, Yy0d11transformer and 12-pulse non-controlled rectifier consist of parallel connection of two 6-pulse rectifiers). These semiconductor units (i.e. both non-controlled rectifiers and AC voltage-controller) can be realized as standard "cheap" commercial converters.

The output DC-choke $\left(\mathrm{Lz}_{\mathrm{Z}}=0.5 \mathrm{mH}\right)$ is used in the DC circuit for purpose to reduce the output DC load current ripple. 


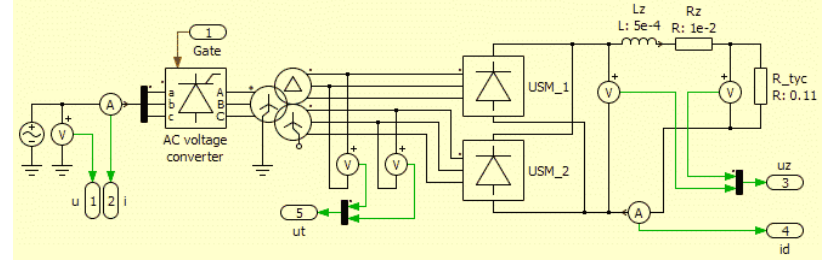

Fig. 1. Diagram of non-controlled 12-pulse rectifier with AC voltageconverter.

The disadvantages of this variant are the high EMCdisturbance (high interference - i.e. non-sinusoidal) of the input AC-currents, high EMC-disturbance of the output DC-currents and especially high reactive power (lagging power factor produced by function of the thyristor AC voltage-converter).

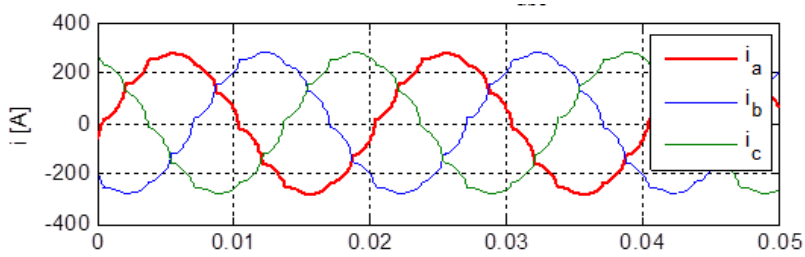

Fig. 2. AC nominal load current (12-pulse rectifier with AC voltageconverter).

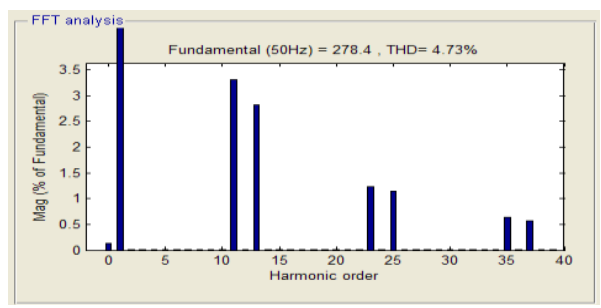

Fig. 3. Harmonic analysis of the nominal current (12-pulse rectifier with AC voltage-converter)

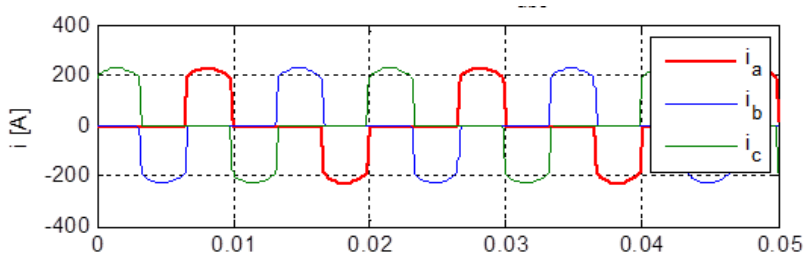

Fig. 4. AC reduced load current (12-pulse rectifier with AC voltageconverter).

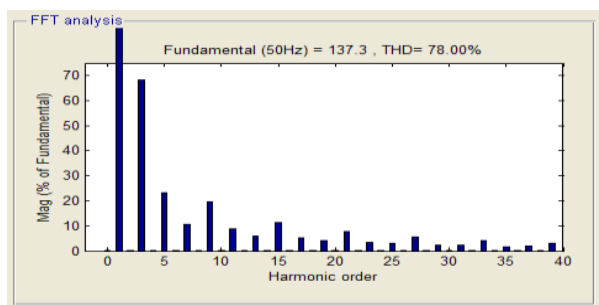

Fig. 5. Harmonic analysis of the reduced load current (12-pulse rectifier with $\mathrm{AC}$ voltage-converter).
Figure 2 shows a relatively small current distortion for nominal power (using of 12-pulse rectifier). But a reduced power regime brings very high EMC-distortion (Fig. 4, 5 for half nominal voltage, half nominal current and quarter nominal output power).

\section{NON-CONTROLLED 6-PULSE RECTIFIER WITH BUCK CONVERTER}

\section{A. Basic Configuration without Additional Inductances}

Figure 6 shows the basic configuration with only one 6-pulse rectifier without additional inductances.

The output power is controlled by a buck converter. This solution brings the using of the DC-capacitor between the rectifier output and buck converter. It yields a high ripple of the input AC-currents and higher order harmonic distortion.

These problems are very similar to the standard cheap commercial solutions of "modern" electric drives (and other similar devices) with diode rectifier frequency converters and voltage source inverter (etc.)

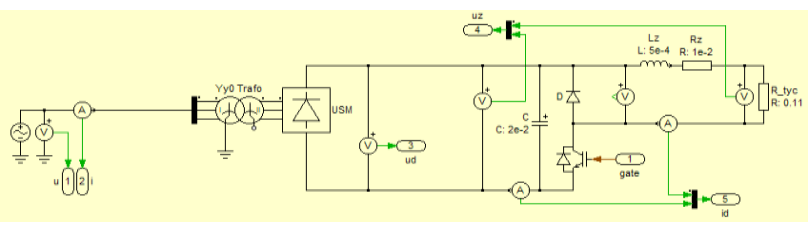

Fig. 6. Diagram of non-controlled 6-pulse rectifier and buck converter on DC-side.

Figure 7 (full-power regime) and Figure 9 (reduced power regime) show the non-sinusoidal input AC-currents.

Low value of inductances (no additional inductances only leaking inductances in the supply transformers) and a big capacitor in the DC-link bring high pulses of quickly charging of this DC-capacitor.

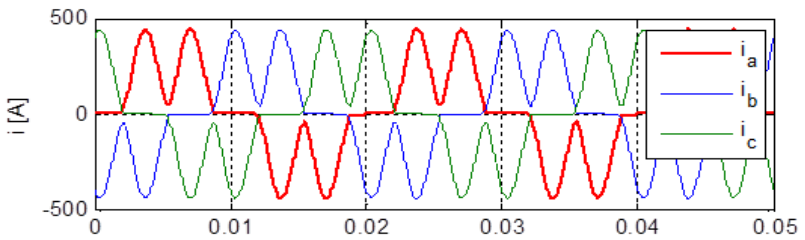

Fig. 7. AC nominal load current (6-pulse rectifier without additional inductances).

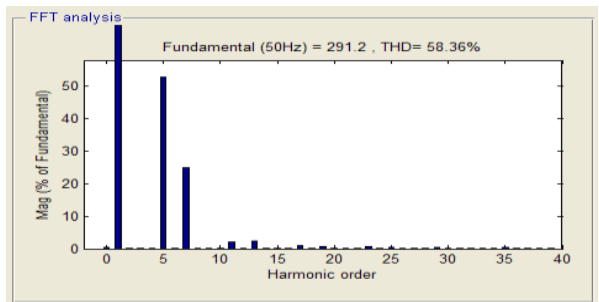

Fig. 8. Harmonic analysis of the nominal current (6-pulse rectifier without additional inductances). 


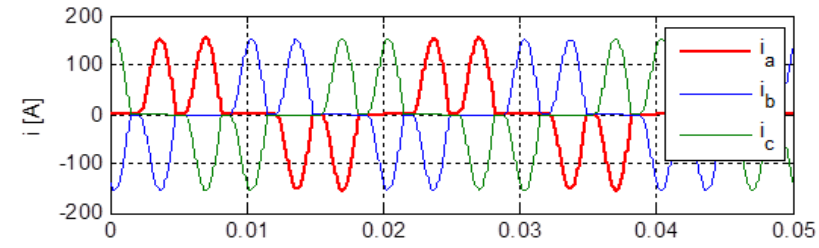

Fig. 9. AC reduced load current (6-pulse rectifier without additional inductances).

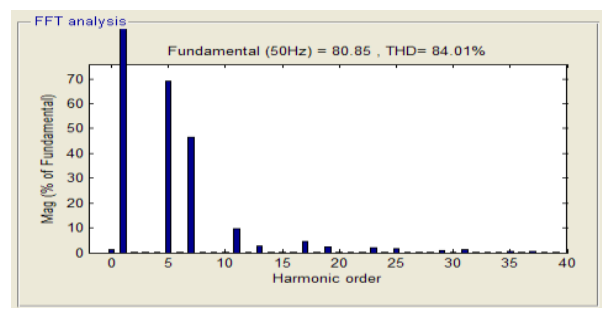

Fig. 10. Harmonic analysis of the reduced load current (6-pulse rectifier without additional inductances).

\section{B. Advanced Configuration with Additional Inductances}

Figure 11 shows the advanced configuration with 3 additional $\mathrm{AC}$-inductances $\mathrm{L}_{\mathrm{V}}$ and one $\mathrm{DC}$ - inductance $\mathrm{L}_{\mathrm{C}}$.

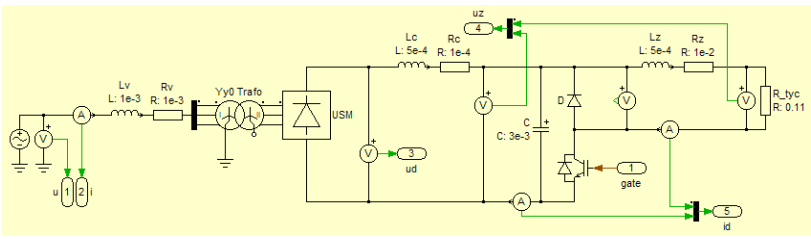

Fig. 11. Diagram of non-controlled 6-pulse rectifier, buck converter on DC-side and additional DC and AC-inductances.

These big inductances reduce the EMC-disturbance (see Fig. 12 for full power and Fig. 14 for reduced power).

Next chapter VII describes the 12-pulse configuration for purpose to obtain smaller values of the total harmonics distortion $\mathrm{THD}_{\mathrm{i}}$ (for input current $\mathrm{i}_{\mathrm{a}}$ ) and reduction of some higher order harmonics components (i.e. especially 5-th and 7-th order harmonics).

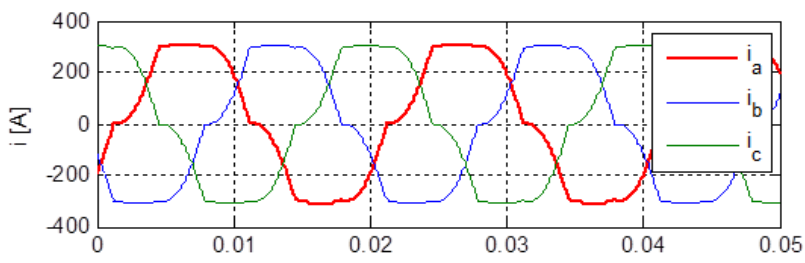

Fig. 12. AC nominal load current (6-pulse rectifier with additional inductances).

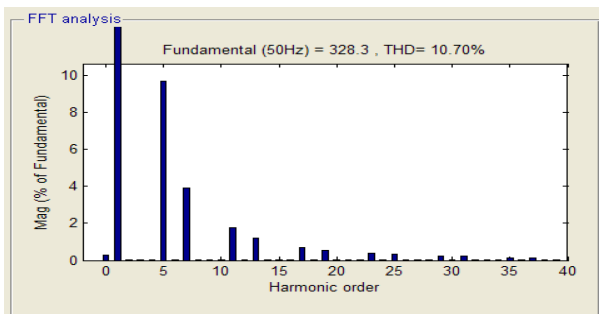

Fig. 13. Harmonic analysis of the nominal current (6-pulse rectifier with additional inductances).

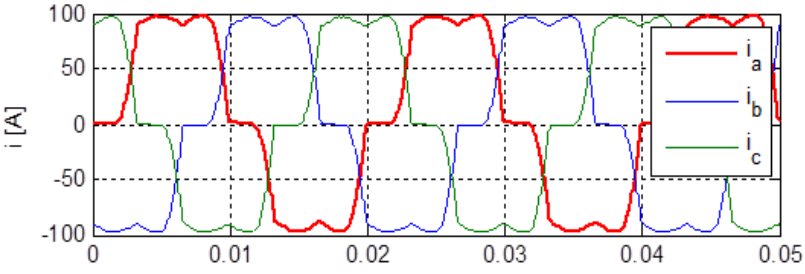

Fig. 14. AC reduced load current (6-pulse rectifier with additional inductances).

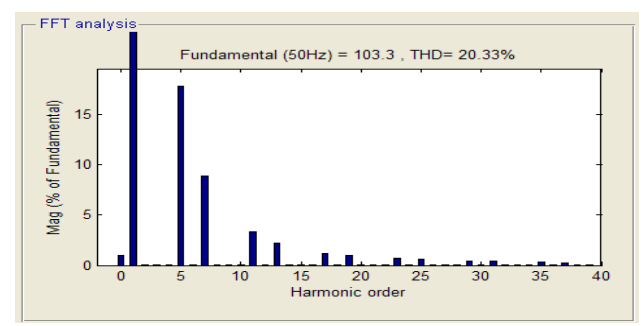

Fig. 15. Harmonic analysis of the reduced load current (6-pulse rectifier with additional inductances)

\section{USING OF 12-PULSE RECTIFIER}

\section{A. Basic Features of 12-pulse Rectifiers}

Using of 12-pulse rectifier brings these advantages:

1) Reduction of the output current ripple: Possibility of using relatively small inductances for purpose to reduce the output current ripple and output voltage ripple (with relatively small capacitor in the DC-link).

2) Reduction of the input current ripple: Possibility of using relatively small inductances for purpose to reduce the input current ripple and reducing of the total harmonic distortion THD.

3) Reduction of number of higher order "characteristic harmonics": The single phase 2-pulse rectifiers produce all odd order harmonics, three phase 6-pulse rectifiers produce 1-st order harmonics, 5-th, 7-th, 11-th,13-th,17-th, 19-th, 23-rd, 25-th,... But the 12-pulse rectifier produces only 1st order harmonics, 11-th, 13-th, 23-rd, 25-th,... see Fig. 16 (i.e. general p-pulse rectifier produces only harmonics of order $\mathrm{h}=\mathrm{k} \cdot \mathrm{p} \pm 1$ ). This reduction of these higher order harmonics brings additionally reduction of the input current total harmonic distortion THD.

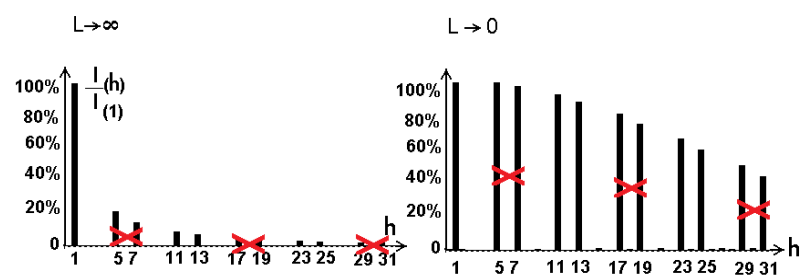

Fig. 16. Typical harmonic analysis of the input currents for the 6-pulse rectifier (original black lines) and for the 12-pulse rectifier (i.e. remaining lines without lines cut by a red cross). The left graph is for a high value of the DC-inductance and the right graph without additional inductances.

The commonly used 12-pulse rectifiers are composed of a either series combination of two 6-pulse rectifiers (for purpose to obtain a high value of the output voltage - for example the DC traction power substation for $3 \mathrm{kV}$ trolley 
wire) or parallel combination of two 6-pulse rectifiers (for purpose to obtain high value of the output current).

Next subchapters describe the difference between these series and parallel variants of the 12-pulse rectifiers.

\section{B. Parallel 12-pulse Rectifier with DC-Inductance}

Figure 17 shows the configuration of the parallel 12pulse rectifier with the additional DC-inductance $\mathrm{L}_{\mathrm{C}}$ (the same value of this inductance as the DC-inductance in Fig.11, but without additional AC-inductances). The output voltage is controlled by the DC-buck converter.

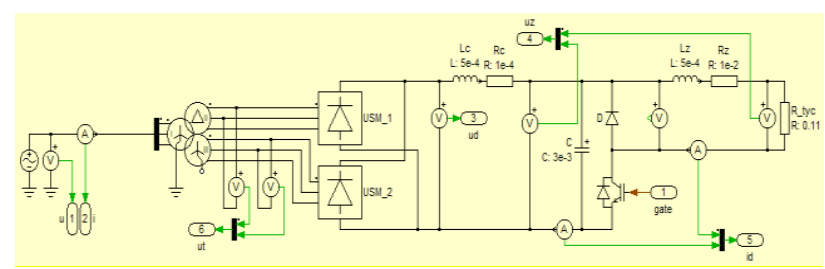

Fig. 17. Diagram of non-controlled 12-pulse rectifier (parallel version) with the additional DC-inductance and buck converter (on DC-side).

Figure 18 shows a small current distortion for the nominal power regime. The input currents are approximately sinusoidal with a very small value of the total harmonic distortion $\mathrm{THD}_{\mathrm{i}}=4.7 \%$.

Figure 20 shows a relatively small current distortion for the reduced output power regime (half nominal voltage, half nominal current and i.e. quarter nominal output power) with the total harmonic distortion $\mathrm{THD}_{\mathrm{i}}=8.8 \%$.

Both these regimes bring better results than the 6-pulse rectifier described in the previous Figs. 11-15 (the same value of the DC-inductance but the 12-pulse rectifier is without additional $\mathrm{AC}$-inductances).

It is possible to obtain better results using the 12-pulse rectifier with additional AC-inductances and mutual inductance between the outputs of both rectifiers.

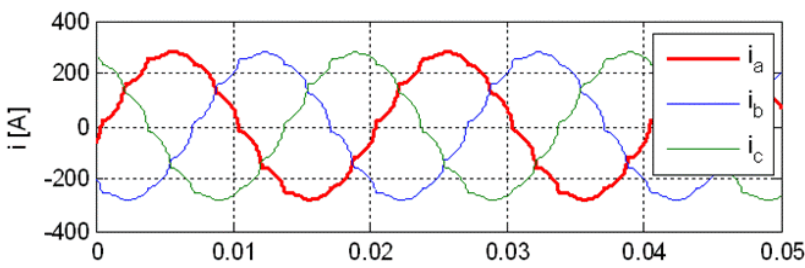

Fig. 18. AC nominal load current (parallel 12-pulse rectifier with additional DC-inductance).

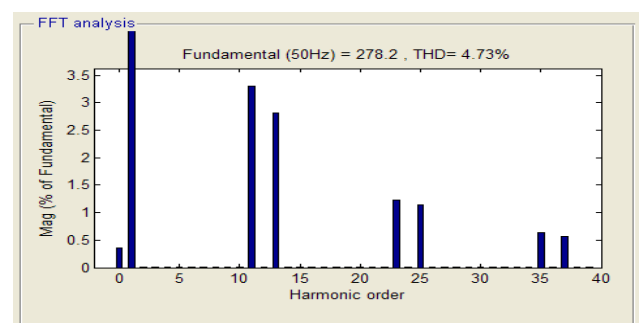

Fig. 19. Harmonic analysis of the nominal current (parallel 12-pulse rectifier with additional DC-inductance).

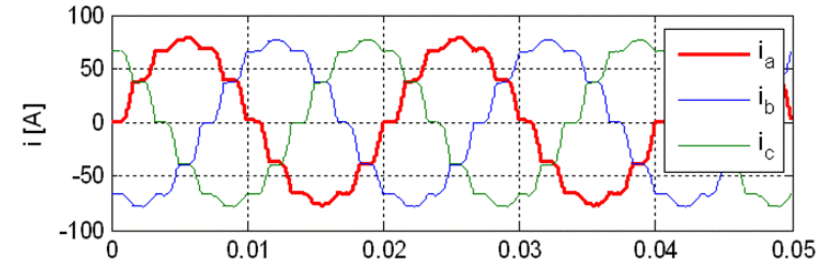

Fig. 20. AC reduced load current (parallel 12-pulse rectifier with additional DC-inductance).

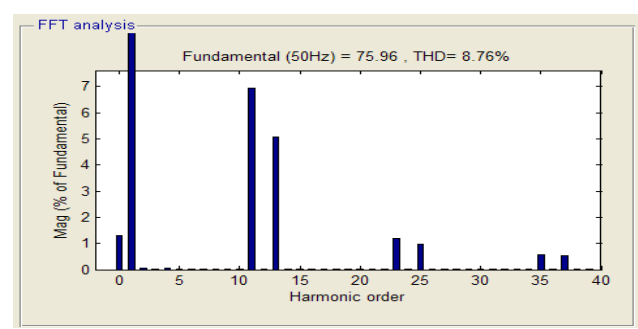

Fig. 21. Harmonic analysis of the reduced load current (parallel 12pulse rectifier with additional DC-inductance).

\section{Series 12-pulse Rectifier with DC-Inductance}

Figure 22 shows the configuration of series 12-pulse rectifier with the additional DC-inductance $\mathrm{L}_{C}$ (the same value of this inductance as the DC-inductance in Fig. 11, but without additional AC-inductances).

The output voltage is controlled by the DC-buck converter (i.e. difference between the previous subchapter is only series connection instead of the previous parallel connection).

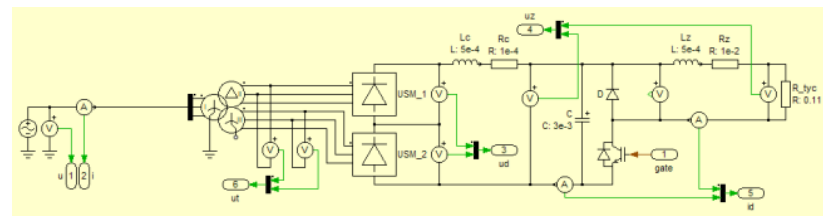

Fig. 22. Diagram of non-controlled 12-pulse rectifier (series version) with additional DC-inductance and buck converter (on the DC-side).

Figure 23 shows a small current distortion for the nominal power regime. The input currents are approximately sinusoidal with a very small value of the total harmonic distortion $\mathrm{THD}_{\mathrm{i}}=10 \%$.

Figure 25 shows a relatively small current distortion for the reduced output power regime (half nominal voltage, half nominal current and i.e. quarter nominal output power) with the total harmonic distortion $\mathrm{THD}_{\mathrm{i}}=12.4 \%$.

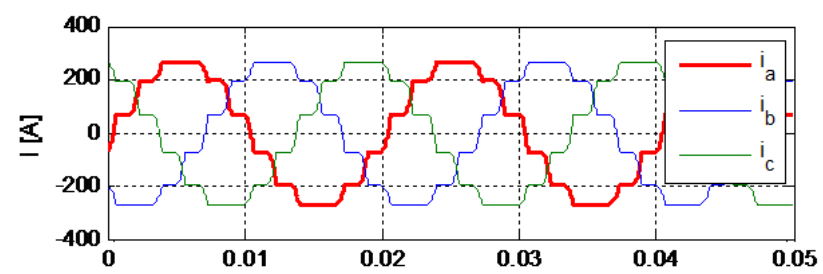

Fig. 23. AC nominal load current (series 12-pulse rectifier with additional DC-inductance). 


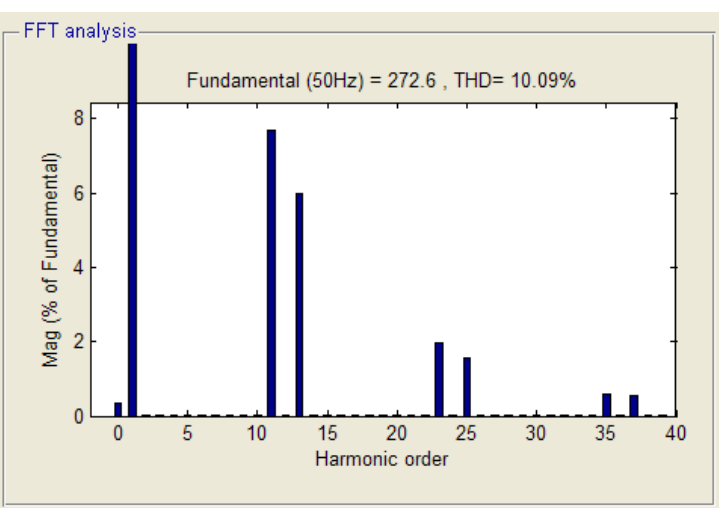

Fig. 24. Harmonic analysis of the nominal current (series 12-pulse rectifier with additional DC-inductance).

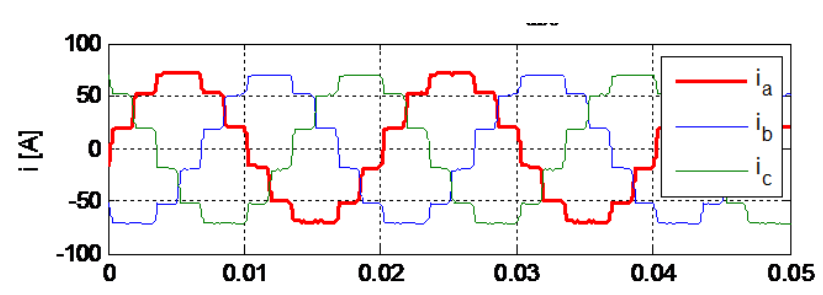

Fig. 25. AC reduced load current (series 12-pulse rectifier with additional DC-inductance).

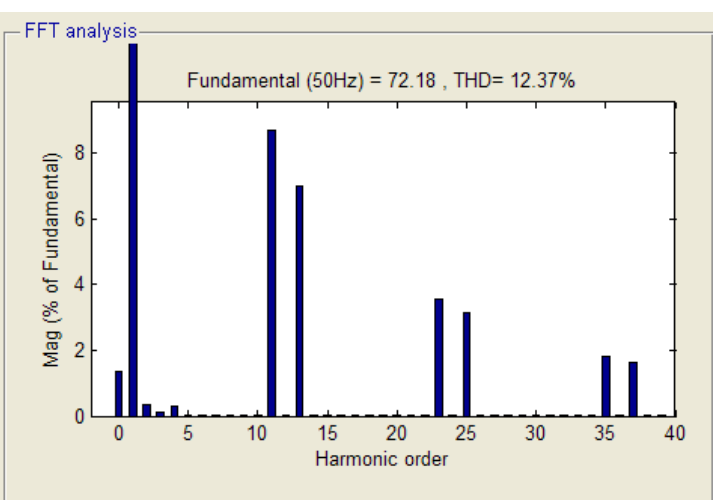

Fig. 26. Harmonic analysis of the reduced load current (series 12-pulse rectifier with additional DC-inductance)

\section{Comparing between Series and Parallel Versions}

The previous parallel version brings better results.

Series version (with additional DC-inductance) brings the input current with approximately 6-step waveforms consisting of rectangular parts with sharp growths.

The parallel version (see previous subchapter B and Figs. 17-21) brings 6-step waveforms consisting of trapezoidal parts with slow growths. This is why the series version has (during each period) only six commutations inside the top 6-pulse rectifier and six commutations inside the bottom 6pulse rectifier. The parallel version has these $6+6$ commutations inside these both 6-pulse rectifiers (left and right) and an extra "external" commutation of the output current between these two 6-pulse rectifiers (left and right rectifiers). It is possible to obtain a longer time of these "external" commutation of the output current between these two 6-pulse rectifiers with slower growths. For this purpose it is possible to use an additional mutual inductance between the outputs of both rectifiers (or two DC-inductances separately for the left and right 6-pulse rectifiers or two 3-phase AC-inductances separately for the left and right 6-pulse rectifiers etc.).

\section{E. Series 12-pulse Rectifier with AC-Inductances}

Figure 27 shows the configuration of the series 12-pulse rectifier with the additional $\mathrm{AC}$-inductances $\mathrm{L}_{V}$ (the same value of this inductance as the AC-inductances in Fig. 11, but without the additional DC-inductance).

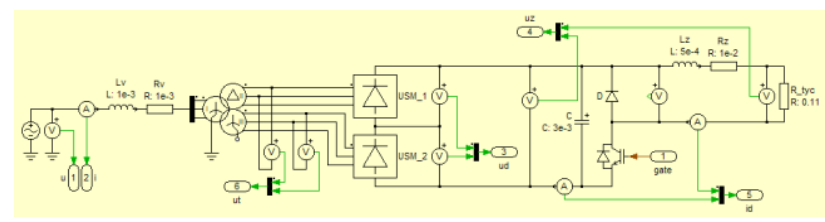

Fig. 27. Diagram of non-controlled 12-pulse rectifier (series version) with additional AC-inductances and buck converter (on DC-side)

Figure 28 shows a small current distortion for the nominal power regime. The input currents are approximately sinusoidal with a very small value of the total harmonic distortion $\mathrm{THD}_{\mathrm{i}}=2.7 \%$.

Figure 30 shows a relatively small current distortion for the reduced output power regime (half nominal voltage, half nominal current and i.e. quarter nominal output power) with the total harmonic distortion $\mathrm{THD}_{\mathrm{i}}=8.1 \%$.

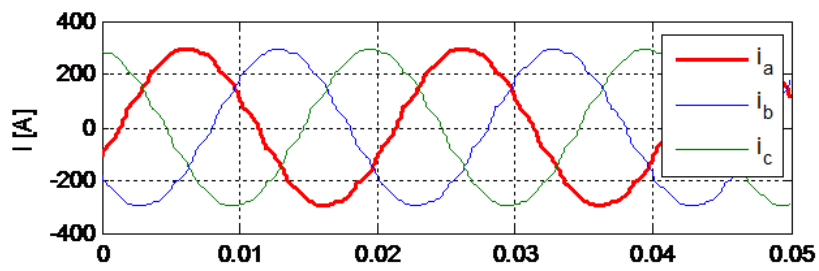

Fig. 28. AC nominal load current (series 12-pulse rectifier with additional AC-inductances).

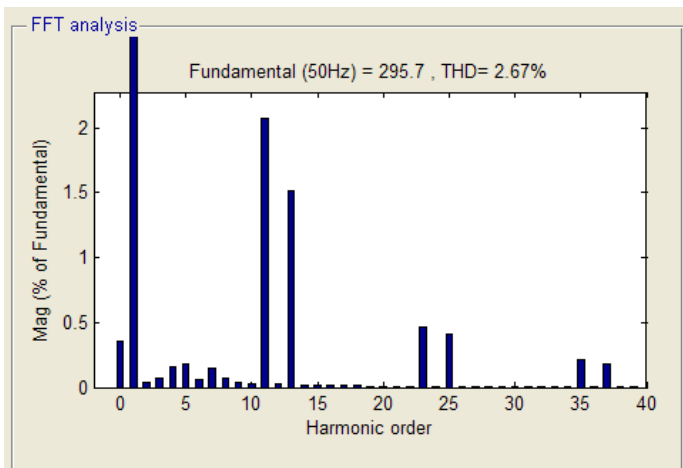

Fig. 29. Harmonic analysis of the nominal current (series 12-pulse rectifier with additional $\mathrm{AC}$-inductances). 


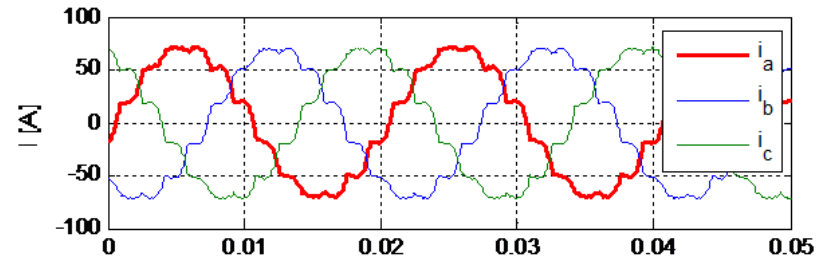

Fig. 30. AC reduced load current (series 12-pulse rectifier with additional AC-inductances).

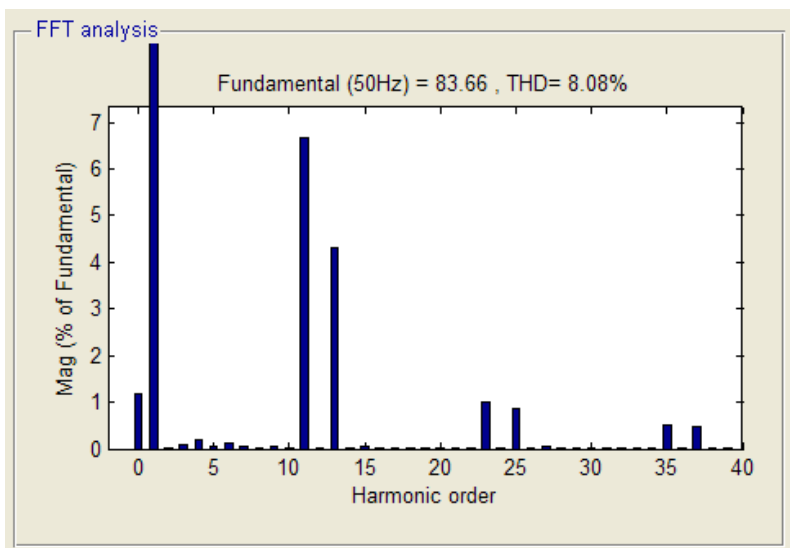

Fig. 31. Harmonic analysis of the reduced load current (series 12-pulse rectifier with additional $\mathrm{AC}$-inductances).

The additional output DC-inductance in the previous subchapter $\mathrm{C}$ (instead input AC-inductances) brings less smoothing of the output currents (this converters used the DC-capacitor for purpose to realize smoothing of the output voltage). But the version with $\mathrm{AC}$-inductances (described in this subchapter) brings the input currents with a very small THD (currents are approximately sinusoidal, because the input current waveforms do not have sharp growths).

\section{F. Series 12-pulse Rectifier with DC and AC-Inductances}

Figure 32 shows the configuration of the series 12-pulse rectifier with the additional input $\mathrm{AC}$-inductances $\mathrm{L}_{\mathrm{V}}$ and additional DC-inductance $\mathrm{L}_{\mathrm{C}}$ (the same value of these inductances in Fig. 11).

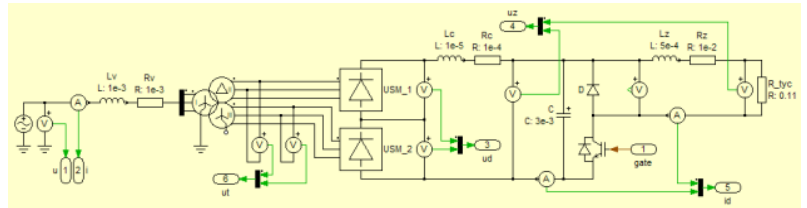

Fig. 32. Diagram of non-controlled 12-pulse rectifier (series version) with additional DC and $\mathrm{AC}$-inductances and buck converter.

Figure 33 shows a small current distortion for the nominal power regime. The input currents are approximately sinusoidal with a very small value of the total harmonic distortion $\mathrm{THD}_{\mathrm{i}}=2.6 \%$.

Figure 34 shows a relatively small current distortion for the reduced output power regime (half nominal voltage, half nominal current and i.e. quarter nominal output power) with the total harmonic distortion $\mathrm{THD}_{\mathrm{i}}=6.6 \%$.

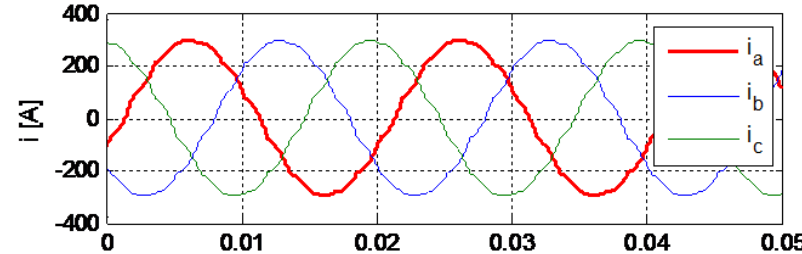

Fig. 33. AC nominal load current (series 12-pulse rectifier with additional DC and AC-inductances).

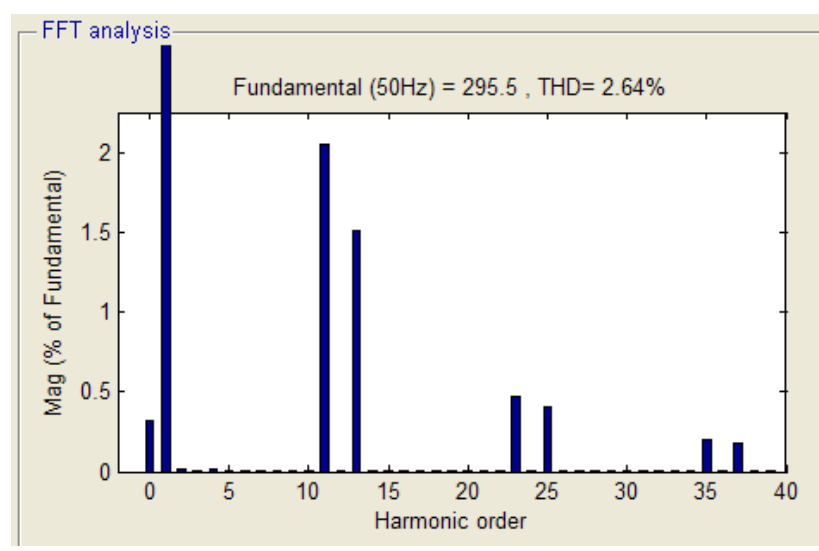

Fig. 34. Harmonic analysis of the nominal current (seriesl 12-pulse rectifier with additional DC and AC-inductances).

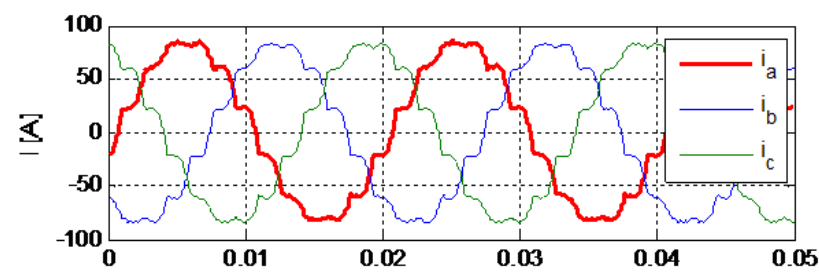

Fig. 35. AC reduced load current (series 12-pulse rectifier with additional DC and AC-inductances).

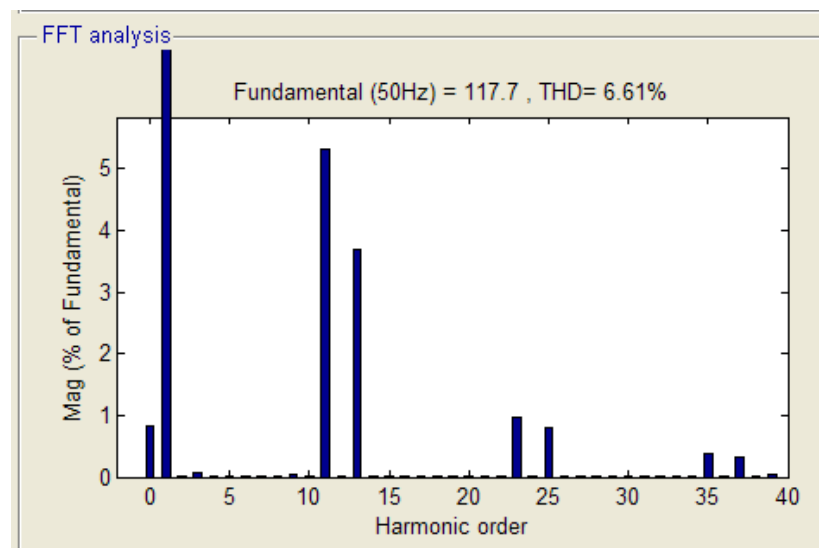

Fig. 36. Harmonic analysis of the reduced load current (series 12-pulse rectifier with additional DC and AC-inductances).

The additional input AC-inductances with the output DC-inductance bring more smoothing of the output currents with a very small THD of the input currents (inputs currents are approximately sinusoidal). 


\section{USING OF ADDITIONAL FILTER}

This chapter shows very simplified example of using the additional LC-filter for purpose to following filtering of the unwanted higher order harmonics.

Figure 37 shows basic configuration with the additional filter designed for the 11-th harmonic $(550 \mathrm{~Hz})$.

This 11-th harmonic has major value of all unwanted higher order harmonics (see Fig. 24 or Fig. 26, Fig. 16 or see previous Fig. 36 etc.).

This filter (see Fig. 38) reduces the value of the 11-th harmonic of the input current (see Fig. 40), because this filter realize approximately a short circuit for this 11-th harmonic.

But the additional filter brings many disadvantages - for example:

1) Possibility of the filter voltage oscillation generated by transient phenomena: Long time dangerous oscillation with very slow damping.

2) Possibility of the unwanted interference with other devices in the supply network: Other non-sinusoidal devices connected to the supply network can generate overloading of this additional filter by higher order current harmonics.

3) Reactive power generated by the filter: This additional LC-filter (with resonant frequency on the 11-th harmonic) produces a high value of the unwanted reactive power (leading power factor) for the fundamental harmonic (i.e. $50 \mathrm{~Hz}$ ), because the capacitors in the LC-filter are charged and discharged by the fundamental harmonic current component.

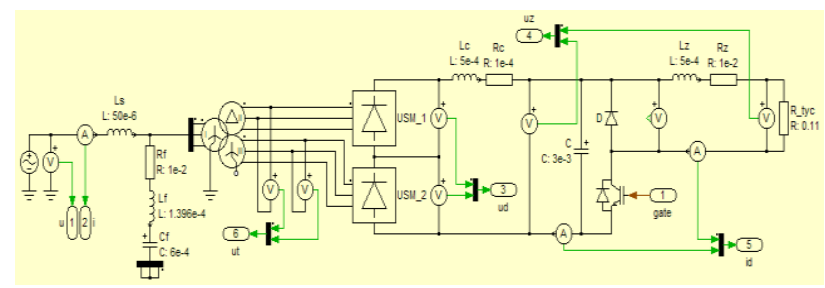

Fig. 37. Diagram of non-controlled 12-pulse rectifier, buck converter on DC-output, additional DC-inductance and additionally LC- filter.

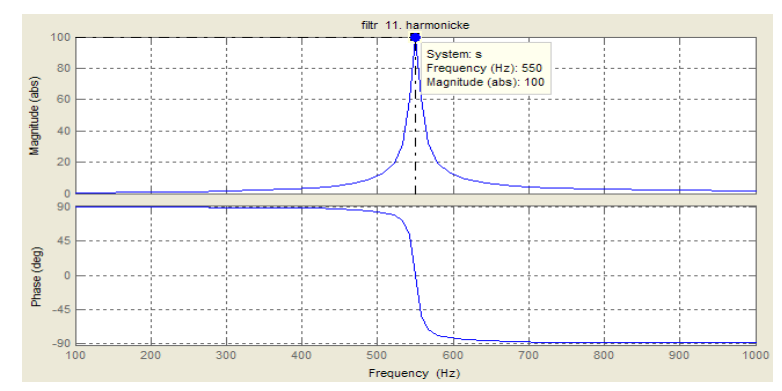

Fig. 38. Frequency characteristic of the filter.

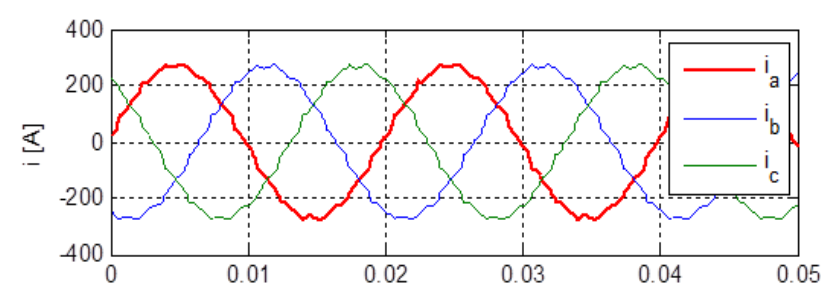

Fig. 39. AC nominal load current.

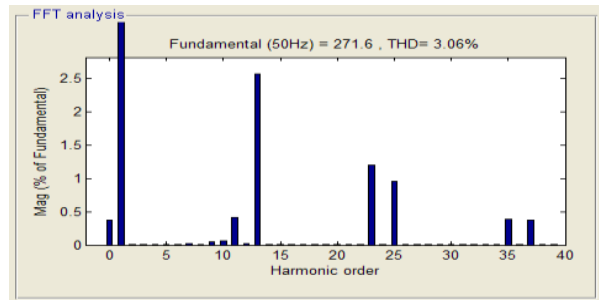

Fig. 40. Harmonic analysis of the nominal current.

\section{MEASUREMENT RESULTS}

\section{A. Description of Measured Laboratory Model}

This chapter presents the results of measurements for some simulated cases. These measurements were realized on a down-scaled laboratory model with two 3-phase voltage regulating transformers (total nominal power $2 \times 30 \mathrm{kVA}$ ). First transformer has Yy0 connection and second transformer Yd1 connection.

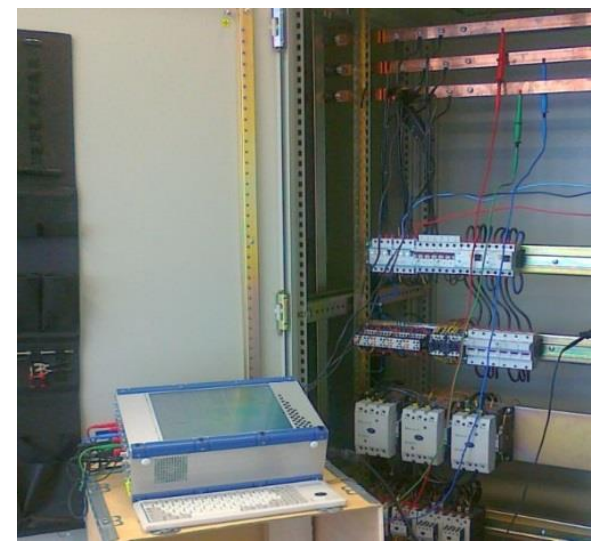

Fig. 41. Measurement of time waveforms and harmonic analysis in the laboratory down scaled model.

Both these transformers have magnetizing currents. Figure 42 shows the waveform for idle running. 


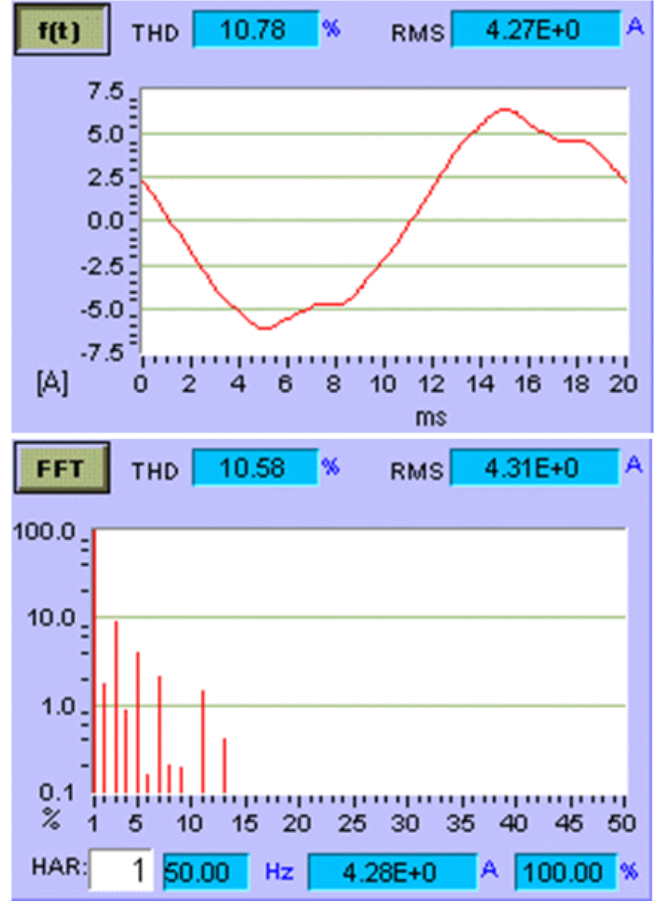

Fig. 42. Input AC current (time waveforms and harmonic analysis) for no-load mode (only magnetizing currents of the transformer with deformation by the magnetizing curve characteristic).

\section{B. Non-Controlled 6-pulse Rectifier}

Figure 43 shows the measured waveform of the total input AC current from supply grid to the 6-pulse version of the rectifier.

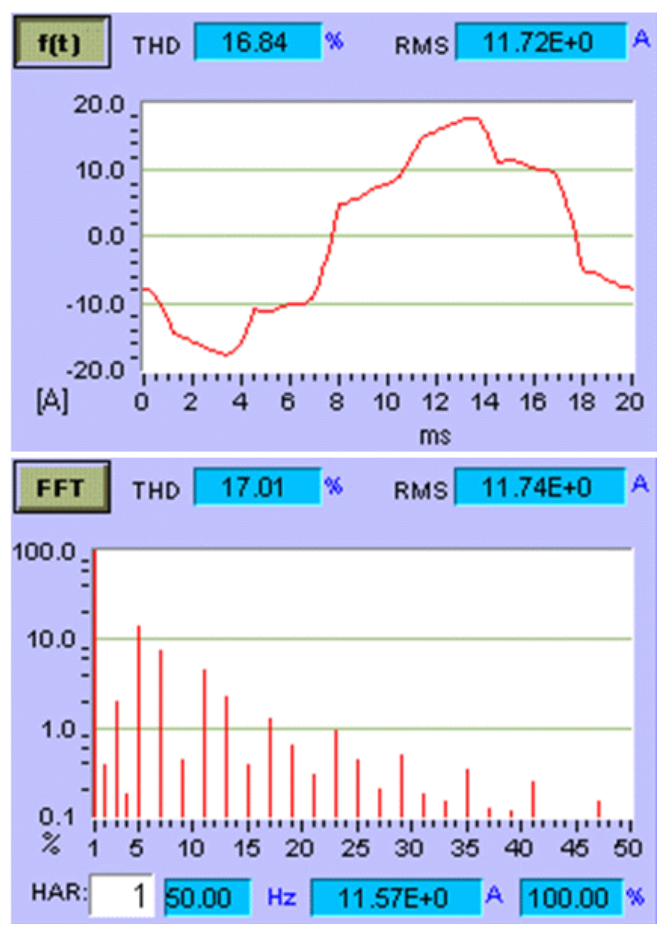

Fig. 43. Input AC current (time waveforms and harmonic analysis) only for the 6-pulse rectifier.

\section{Non-Controlled 12-pulse Rectifier}

Figure 44 shows the measured waveform of the total input AC current from the supply grid to the 12-pulse version of the rectifier (series connection).

In both cases also the generalized harmonic distortion $\mathrm{THD}_{\text {I }}$ reflects the expected results.

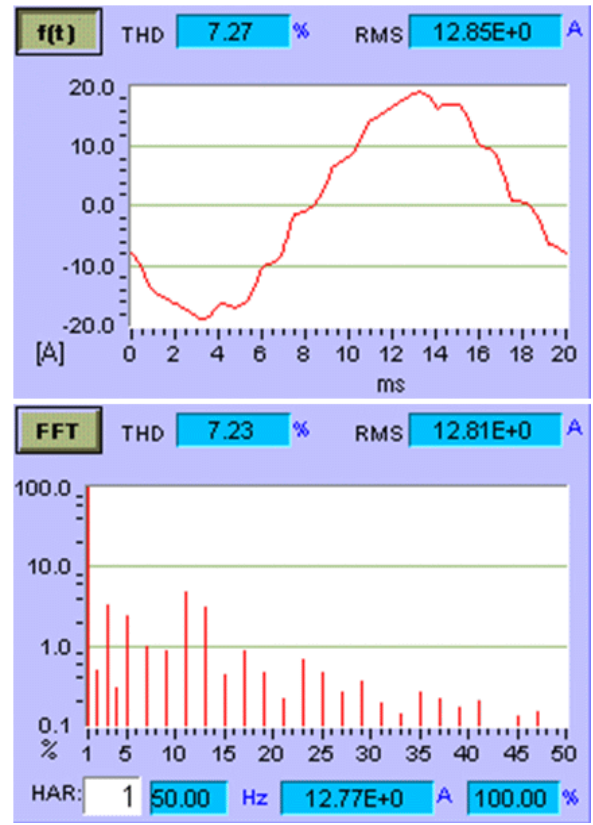

Fig. 44. Input AC current (time waveforms and harmonic analysis) for the 12-pulse rectifier.

\section{CONCLUSION}

This paper compares some variants of the power circuits for the high power DC source $(1 \mathrm{kA} / 110 \mathrm{~V})$ with a reduced disturbance generated from the converter to the supply network.

The thyristor converters bring problems of the unwanted higher order harmonics and reactive power (of lagging power factor). Best results are achieved by using noncontrolled rectifiers with the additional DC buck-converter.

The 12-pulse rectifiers (series or parallel version) bring many advantages (for example less output current ripple, less input current ripple, less produced EMC-disturbance and $\mathrm{THD}_{\mathrm{i}}$ ).

\section{ACKNOWLEDGMENT}

This research has been supported by project No SGS-2015-038.

\section{REFERENCES}

[1] J. Arrilaga, D. A. Bradley, and P. S. Bodger, Power system harmonics. Wiley - Interscience Publication, 1985.

[2] M. Bauta and M. Grötzbach, "Noncharacteristic line harmonics of AC/DC converters with high DC current ripple," in 8th IEEEICHQP, Athens, Proc. Vol. II, pp. 755-760, 1998.

[3] A. Bitoleanu, M. Popescu, and D. Marin, "Interface Filter Design for shunt active power filters," Advances in Electrical and Computer Engineering, Volume 10, Issue 3, pp. 55-60. https://doi.org/10.4316/aece.2010.03009 
[4] N. Brejcha, "Use of the buck converter in AC circuits," in 11th International Scientific Conference on Electric Power Engineering 2010, Brno, Czech Republic 04-06, 2010, pp. 827-831.

[5] P. Drábek, M. Pittermann, and J. Fořt, "Behaviour of the AC/DC converter from the low frequency interference point of view," in $X V I$ International conference on electromagnetic disturbances: EMD 2006, Proceedings Book Series: International Conference on Electromagnetic Disturbances - Proceedings, pp. 88-89.

[6] A. Kloss, Stromrichter-Netzruckwirkungen in Theorie und Praxis. Aarau: AT-Verlag, 1981

[7] A. Kloss, Oberschwingungen. Berlin: VDE-Verlag, 1989.

[8] V. Kus and B. Skala, "Effect of filter and compensation unit in the traction power supply at extreme distortion," in 2013 International Conference-Workshop Compatibility And Power Electronics, Ljubljana, 2013, pp. 7-12. ISBN 978-1-4673-4913-0. https://doi.org/10.1109/CPE.2013.6601120

[9] V. Kus, B. Skala, and J. Hammerbauer, Electromagnetic compatibility of the power electronic systems (in Czech). Praha: BEN, 2013, ISBN 978-80-7300-476-7.

[10] V. Kus, P. Drabek, J. Fort, and M. Pittermann, "Harmonic currents of frequency converters with voltage source inverters," in International XV Symposium Micromachines and Servosystems, Warszawa: Electrotechnical Institute, Warsaw, Poland, 2006. pp. 4550. ISBN 83-922095-1-6.

[11] V. Kus, T. Josefova, and P. Bilik, "Harmonic currents generated by the voltage-source active rectifier," in 2013 Fourth International
Conference on Power Engineering, Energy and Electrical Drives (POWERENG), 13-17 May 2013, pp.373-378.

https://doi.org/10.1109/PowerEng.2013.6635635

[12] V. Kus and T. Josefova, "The use of theory of frequency modulation for the calculation of current harmonics of the voltage-source active rectifier," in 2013 International Conference on Applied Electronics (AE), 10-12 Sept. 2013, pp.1-4.

[13] V. Kus, Impact of power electronic converters on power distribution network (in Czech). Praha: BEN, 2002.

[14]N. Mohan, T. M. Undeland, and W. P. Robbins, Power electronics converters, applications and design. John Wiley\&Sons, Inc. 2003.

[15]B. Singh, B. Singh, A. Chandra, K. Al-Haddad, A. Pandey, and D. Kothari, "A review of single-phase improved power quality AC DC converters," IEEE Transactions on Industrial Electronics, vol.50, no.5, pp. 962-981, Oct. 2003. https://doi.org/10.1109/TIE.2003.817609

[16]F. Vondrášek, Výkonová elektronika. Svazek 2 - Měniče s vnějši komutaci (in Czech). Skripta ZČU v Plzni, 2001, ISBN 80-7082-6959.

[17] G.J. Wakileh, Power systems harmonics: fundamentals, analysis and filter design. Berlin: Springer, 2001. ISBN 3-540-42238-3. https://doi.org/10.1007/978-3-662-04343-1

[18]J. Fořt and M. Pittermann, "Výkonový stejnosměrný regulovaný zdroj 113kW / 1kA," in XXXV. konference o elektrických pohonech, Plzeň 6.-7.6.2017, pp. 1-22 (version on CD-disk). 